\title{
UBL1, a Human Ubiquitin-like Protein Associating with Human RAD51/RAD52 Proteins
}

\author{
Zhiyuan Shen, ${ }^{*}$ Paige E. Pardington-Purtymun,* Jarmon C. Comeaux,* \\ ROBERT K. MOYZS, † AND DAVID J. CHEN*,1 \\ *DNA Damage and Repair Group, Life Sciences Division, and †Center for Human Genome Studies, \\ Los Alamos National Laboratories, Los Alamos, New Mexico 87545
}

Received February 16, 1996; accepted June 13, 1996

The RAD51/RAD52-dependent DNA repair pathway is involved in DNA recombination and DNA doublestrand break repair in yeast. Although many proteins in the RAD51/RAD52-dependent DNA repair pathway have been identified in yeast, a novel protein(s) that functions with RAD51/RAD52 may also exist in humans. Using a yeast two-hybrid system, we have identified a 12-kDa protein that associates with the human RAD51 and RAD52 proteins. This protein shares significant amino acid homology with the yeast protein SMT3, which functionally associates with the yeast mitosis fidelity protein MIF2. It also shares moderate homology with ubiquitin and several other proteins, including the $\mathrm{N}$-terminus of the RAD23 protein and a ubiquitin cross reacting protein. Therefore, the gene is tentatively designated UBL1 for ubiquitin-like 1 . The UBL1 mR NA is expressed in many human tissues, most highly in testis. The UBL1 gene is mapped to chromosome 2q32.2-q33, and a related sequence may be located on chromosome 1q23-q25. 1996 Academic Press, Inc.

\section{INTRODUCTION}

DNA double-strand break (DSB) ${ }^{2}$ is one of the most important forms of DNA damage caused by ionizing radiation. Efficient repair of DSB is essential for the cell to recover from radiation damage. In yeast, the RAD52 epistasis group genes encode proteins involved in DSB repair and recombination (Friedberg et al., 1991). Several yeast genes in the RAD52-dependent repair pathway have been cloned. These include RAD50, RAD51, RAD52, RAD53 (SPK1), RAD54,

Sequence data from this article have been deposited with the GenBank/EMBL Data Libraries under Accession No. U38784.

${ }^{1}$ To whom correspondence should be addressed at LS-6, MS M888, Life Sciences Division, Los Alamos National Lab, Los Alamos, NM 87545. Telephone: (505) 667-2789. Fax: (505) 665-3024. E-mail: dchen@telomere.lanl.gov.

${ }^{2}$ Abbreviations used: DSB, DNA double-strand break; UBL1, a ubiquitin-like protein 1, $12 \mathrm{kDa}$; Gal4-DA, the DNA activation domain (amino acids 768-881) of Gal-4 protein; Gal4-DB, the DNA binding domain (amino acids 1 - 147) of Gal-4 protein; LacZ, $\beta$-galactosidase gene; MMS, methyl methanesulfonate.
RAD55, and RAD57 (Adzuma et al., 1984; Alani et al., 1989; Basile et al., 1992; Emery et al., 1991; Kans and Mortimer, 1991; Lovett, 1994; Schild et al., 1983; Shinohara et al., 1992; Zheng et al., 1993). It is known that RAD51 is a RecA-like protein that has DNA-binding, ATP-binding, and DNA strand-exchange activities, while RAD54 contains regions homologous to DNA helicase. Interactions among RAD52, RAD51, RAD55, and RAD57 have been identified (Firmenich et al., 1995; Hays et al., 1995; Shinohara et al., 1992; Smith and Rothstein, 1995). RAD52 and RAD54 are highly expressed during yeast meiosis (Cole et al., 1989). Yeast RAD51 and RAD53 also have cell-cycle-dependent expression (Basile et al., 1992; Zheng et al., 1993), and RAD53 also participates in cell cycle control (Sanchez et al., 1996).

In humans, only RAD51 and RAD52 have been reported (Muris et al., 1994; Shen et al., 1995; Shinohara et al., 1993). The human RAD51 protein has activities similar to those of yeast RAD51, including DNA binding and a specific interaction with RAD52 protein (Benson et al., 1994; Shen et al., 1996a). Also, we have found that human RAD52 protein self-associates (Shen et al., 1996b). More recently, RAD51 has been shown to accumulate in the synaptonemal complex, indicating involvement of RAD51 in meiosis and chromosome re combination (Haaf et al., 1995). Human RAD52 overexpression in monkey cells enhances their resistance to radiation and increases the frequency of homologous recombination (Park, 1995). However, little is known about how these interactions might fit into the context of DSB repair.

The importance of DSB repair factors is not limited to their roles in modulating radiation sensitivity, but includes their roles in DNA recombination, in repair of alkylating and cross-linking agent-induced DNA damage, and in some physiological processes. For example, mutations in the yeast RAD52 group genes result in increased sensitivity to the alkylating agent methyl methanesulfonate (MMS). Indeed, the yeast RAD52 gene was cloned by its ability to complement MMS sensitivity (Adzuma et al., 1984; Schild et al., 1983). The RAD52 gene has been found to function in plasmid 
recombination induced by the cross-linking agent psoralen (Han and Saffran, 1992; Saffran et al., 1992). In mammalian immune systems, various types of antibody genes or antigen receptor genes are generated by $\mathrm{V}(\mathrm{D})$ J rejoining, where a DNA strand-break is introduced, and the DSB repair machinery complies. In other cases, integration of viral DNA into the host genome may require DSB repair-associated mechanisms. During meiosis, mechanisms of chromosome exchange (recombination) may overlap with DSB repair. However, the mechanism of the RAD52-associated repair pathway is poorly understood, especially in human cells.

To elucidate the DSB repair mechanism in humans, one of the first steps is to identify human proteins involved in DSB repair. It is assumed that some proteins involved in the same repair pathway may associate with each other in the cells. Therefore, one strategy to identify novel proteins participating in the RAD51/ RAD52-dependent repair pathway is to identify proteins that actually interact with known proteins, such as RAD51 and RAD52. We have initiated experiments to identify a RAD51/RAD52 interacting protein(s) by using the yeast two-hybrid approach. This approach would also identify a gene(s) involved in meiosis. In this article, we report the cDNA cloning of a ubiquitinlike gene by using the two-hybrid approach. This gene is designated UBL1 for ubiquitin-like 1, as recommended by the Human Gene Nomenclature Committee. Tissue-specific mRN A expression shows that UBL 1 expresses highest in testis. By FISH analysis using a CDNA probe and PCR analysis using a panel of mouse hybrid cells that contain a single human chromosome, the UBL 1 gene was mapped to chromosome 2q32.2q33; a related sequence may be located on chromosome 1q23- q25.

\section{MATERIALS AND METHODS}

Materials. The yeast strains SFY526 (MATa; ura3-52; his3-200; ade2-101; Iys 2-801; trp 1-901; leu2-3,112; can'; gal4-542; gal80-538; URA3::GAL 1-LacZ) and HF 7c (MATa, ura3-52; his3-200; Iys2-801; ade2-101; trp1-901; leu2-3,112; gal4-542; gal80-538; LYS2::GAL 1HIS3; URA3::(GAL4 17mers) ${ }_{3}-\mathrm{CYC} 1-\mathrm{L}$ acZ) were purchased from Clontech Laboratories (Palo Alto, CA). SFY 526 has a LacZ reporter gene fused downstream of the Gal-1 promoter. HF 7c has a His reporter gene controlled by a Gal-1 promoter and a LacZ reporter gene controlled by a CYCl promoter. The Gal-4 DNA activation domain (Gal4-DA) fused CDNA library in pACT vector was also purchased from Clontech. Two hybrid vectors for RAD51 and RAD52 proteins have been previously reported (Shen et al., 1996a,b). SD and YPD media/plates were prepared as described in the two-hybrid system manual (Clontech Laboratories Inc.).

Library screen using the yeast two-hybrid system. The library screening for this yeast two-hybrid system was performed according to the Matchmaker Kit manual (Clontech Laboratory Inc.). Briefly, HF 7c yeast was first transfected with pGBT9/RAD51 expressing the Gal4-DB/RAD51 fusion protein using the polyethylene glycol/lithium acetate method. Yeast HF 7c with pGBT9/RAD51 was subsequently transfected with cDNAs isolated from the pACT library. These cotransfected yeast were grown in $\mathrm{SD} / \mathrm{Try}^{-} / \mathrm{Leu}^{-} / \mathrm{His}^{-}$agar plates. A positive clone in $\mathrm{SD} / \mathrm{Trp}^{-} / \mathrm{Leu}^{-} / \mathrm{His}^{-}$should contain a $\mathrm{pACT}$ plasmid coding for a Gal4-DB/RAD51 interacting protein or a protein that is able to activate the reporter gene (His) without the RAD51 protein.

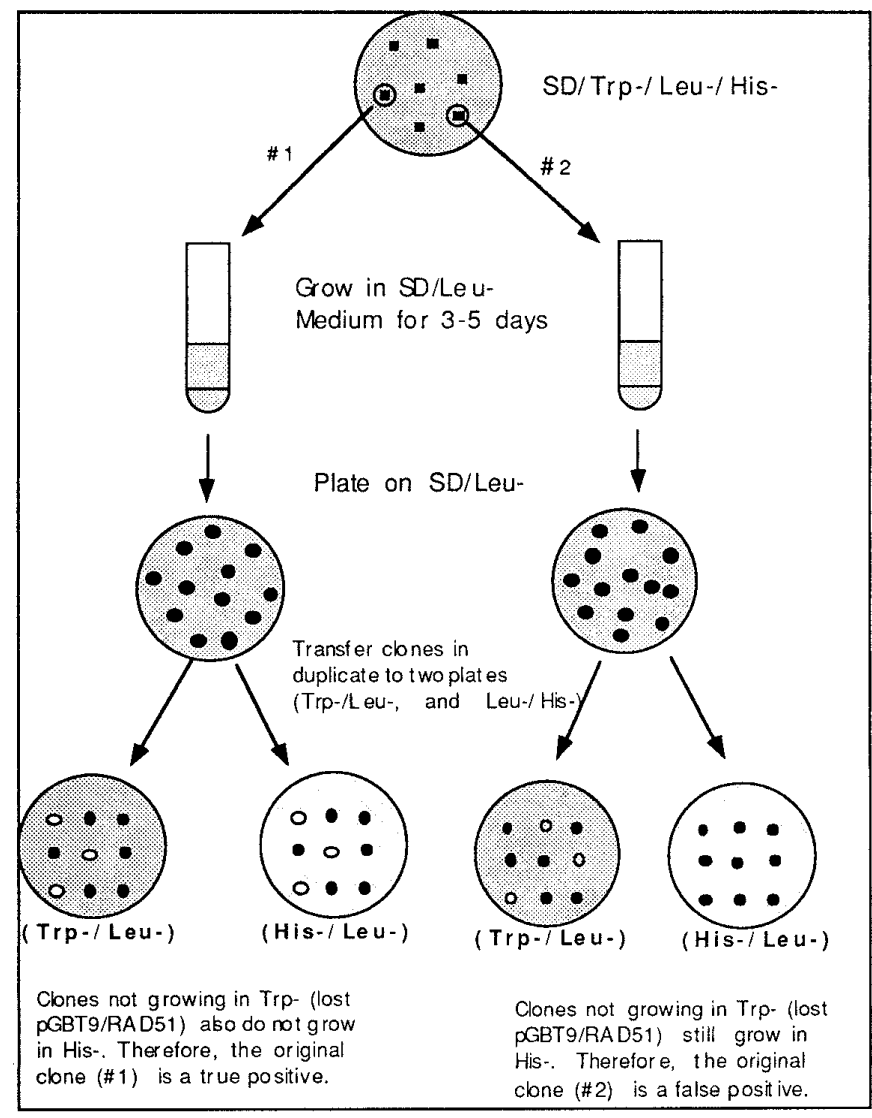

FIG. 1. Procedures to eliminate false positives in a yeast twohybrid screen. See text for details.

The second case is a false positive and was to be eliminated. To do this, the procedure illustrated in Fig. 1 was used. A clone grown on $\mathrm{SD} / \mathrm{Trp}^{-} / \mathrm{Leu}^{-} / \mathrm{His}^{-}$was grown in SD/Leu medium for 5 days and then plated onto SD/Leu ${ }^{-}$agar plates. Due to Try auxotrophs, some of the yeast grown on SD/Leu ${ }^{-}$agar plates may have lost plasmid pGBT9/RAD51(Trp ${ }^{+}$). Then, 25 individual colonies from SD/Leu plates were duplicately transferred ontoSD/Try ${ }^{-} / \mathrm{Leu}^{-}$and SD/Leu ${ }^{-} /$ $\mathrm{His}^{-}$agar plates in an organized manner. When the original clone on $\mathrm{SD} / \mathrm{Trp}^{-} / \mathrm{Leu}^{-} / \mathrm{His}^{-}$is a true positive, these clones from SD/Leu plates, which do not grow in SD/Trp ${ }^{-} / \mathrm{Leu}^{-}$(i.e., have lost pGBT9/ RAD51), will also not grow in SD/Leu $/ / \mathrm{His}^{-}$. If the original clone on $\mathrm{SD} / \mathrm{Trp}^{-} / \mathrm{Leu}^{-} / \mathrm{H}^{-} \mathrm{s}^{-}$plate is a false positive, a colony will grow in SD/ $\mathrm{Leu}^{-} / \mathrm{His}^{-}$even if it has lost pGBT9/RAD51 (i.e., not grown in SD/ $\operatorname{Trp}^{-} / \mathrm{Leu}^{-}$). Therefore, true positive clones were identified. The pACT plasmids from positive yeast clones were isolated and electroporated into HB101 cells, from which a large-scale purification of pACT plasmids was performed. The isolated plasmids were then subjected to automated DNA sequencing, as will be described later.

In vivo assay of protein interaction using the yeast two-hybrid system. A description of the protein interaction assay using the yeast two-hybrid system can be found in the manufacturer's Matchmaker manual (Clontech Laboratories) and previous publications (Shen et al., 1996a,b). Briefly, plasmids for the two fusion constructs (one fused with the Gal4-DB, the other fused with Gal4-DA) were cotransfected into the genetically constructed yeast cells SFY526. Transformed yeast cells were grown on $\operatorname{Trp}^{-} / \mathrm{Leu}^{-}$synthetic agar plates for 3 days to select yeast clones bearing both fusion vectors. To measure the expression of the $\beta$-galactosidase ( $L a C Z)$ reporter gene, which correlates with the interaction of two fusion proteins expressed from these two vectors, LacZ activity in three independent transformants was measured by filter assay (see Matchmaker Manual; and Shen et al., 1996a,b). Quantitative LacZ activity in Miller's unit (Miller, 1972) was assayed according to the Matchmaker kit manual (Clontech Laboratories). Briefly, yeast froma single clone were grown 
overnight in synthetic media lacking Trp/Leu. The density of yeast was determined by measuring the absorbance at $600 \mathrm{~nm}$. Then, 0.1 $\mathrm{ml}$ of culture was mixed with $0.7 \mathrm{ml}$ of Z-buffer $\left(16.1 \mathrm{~g} / \mathrm{liter} \mathrm{Na}_{2} \mathrm{H}\right.$ $\mathrm{PO}_{4} \cdot 7 \mathrm{H}_{2} \mathrm{O} ; 5.5 \mathrm{~g} / \mathrm{liter} \mathrm{NaH}_{2} \mathrm{PO}_{4} \cdot \mathrm{H}_{2} \mathrm{O} ; 0.75 \mathrm{~g} / \mathrm{liter} \mathrm{KCl} ; 0.246 \mathrm{~g} / \mathrm{liter}$ $\left.\mathrm{MgSO}_{4} \cdot 7 \mathrm{H}_{2} \mathrm{O} ; \mathrm{pH} 7.0\right), 50 \mu \mathrm{l}$ of $\mathrm{CHCl}_{3}$, and $50 \mu \mathrm{l}$ of $0.1 \%$ SDS. ONitrophenylgalactoside ( $4 \mathrm{mg} / \mathrm{ml}$ ) was used as substrate for LacZ. After $2 \mathrm{~h}$ of $30^{\circ} \mathrm{C}$ incubation, the reaction mix was centrifuged, and the absorbance of the supernatant was read at $420 \mathrm{~nm}$. The LacZ in Miller's unit was calculated as $1000 \times$ [OD 420/(t $\times \mathrm{V} \times$ OD 600], where $t$ is time of incubation, $V$ is volume of yeast culture, and OD 600 is the absorbance of yeast culture at $600 \mathrm{~nm}$.

Chromosome localization by cDNA FISH mapping. To map the chromosome, the protocol described by Heng et al . was used (Heng et al., 1992; Heng and Tsui, 1993, 1994). Briefly, human Iymphocytes were synchroni zed with phytohemagglutini n, and metaphase spreads were made by standard procedures. cDNA probe was biotinylated with dATP using the BRL BioNick labeling kit and hybridized to the chromosome slides. The FISH and DAPI signals were photographed separately. The DAPI chromosome pictures were superimposed on the FISH signal pictures to localize the region better.

DNA sequencing. A primer-walking strategy was used to sequence cloned plasmid cDNA inserts. Sequencing was performed with the Taq DyeDeoxy Terminator Cycle Sequencing Kit and the ABI 373A automatic DNA sequencer (Applied Biosystems Inc., Foster City, CA) according to the manufacturer's protocols. Both CDNA strands were sequenced at least once. Sequence editing was performed with the SeqE d software (Applied Biosystems) on a Macintosh computer. Further sequence analysis was performed using the GCG sequence analysis software package (University of Wisconsin, Madison, WI).

Northern hybridization. A multiple-tissue Northern blot containing mRNA from leukocyte, colon, small intestine, ovary, testis, prostate, thymus, and spleen was purchased from Clontech Laboratories. This membrane was sequentially hybridized with UBL1

61
12
1
181
39
241
59
301
79
361
99
421
481
541
601
661
721
781
841
901
961

GGAGCGAGGTTCTGCTTACCCGAGGCCTCTGCTGTGCGGAGACCCCCGGGTGAAGCCACC GTCATCATGTCTGACCAGGAGGCCAAACCTTCAACTGAGGACTTGGGGGATAAGAAGGAA MetSerAspgInGIUALaLYSP roSerThrGIUAspLeuGI YAsPLYSLYSGI

121 GGTGAATATATTAAACTCAAAGTCATTGGACAGGATAGCAGTGAGATTCACTTCAAAGTG

19 GIYGIuTYrIIeLYSLeuLysValIleGlyGInAspSerSerGluIleHisPheLysVal

181 AAAATGACAACACATCTCAAGAAACTCAAAGAATCATACTGTCAAAGACAGGGTGTTCCA LysMetThrThrHisLeuLysLysLeuLysGluSerTy YCYsGInArgGInGIYValPro

241 ATGAATTCACTCAGGTTTCTCTTTGAGGGTCAGAGAATTGCTGATAATCATACTCCAAAA MetAsnSerLeitArgPheLeuPheGluGlyGlnArgIleAlaAspAsnHisThrP roLys GAACTGGGAATGGAGGAAGAAGATGTGATTGAAGTTTATCAGGAACAAACGGGGGGTCAT GIuLeuGIYMetGluGluGluAspValIleGluValTyrGlnGluGlnThrGIYGIYHis TCAACAGTTTAGATATTCTTTTTATTTTTTTTCTTTTCCCTCAATCCTTTTTTATTTTTA SerThrVaI ***

AAAATAGTTCTTTTGTAATGTGGTGTTCAAAACGGAATTGAAAACTGGCACCCCATCTCT TTGAAACATCTGTA TGCTATT TACGTGTGCACAGAGAGGTCACCTTTTTCAGGACATTGCATTTTCAGGCTTGTGGTGATA TACGTGTGCACAGAGAGGTCACCTTTTTCAGGACATTGCATTTTCAGGCTTGTGGTGATA AATAAGATCGACCAATGCAAGTGTTCATAATGACTTTCCAATTGGCCCTGATGTTCTAGC CTGAACTGTGGAAAAATGACCTTTCCTTAACTTGAAGCTACTTTTAAAATTTGAGGGTCT GGACCAAAAGAAGAGGAATATCAGGTTGAAGTCAAGATGACAGATAAGGTGAGAGTAATG ACTAACTCCAAAGATGGCTTCACTGAAGAAAAGGCATTTTAAGATTTTTTTAAAAATCTTG TCAGAAGATCCCAGAAAAGTTCTAATTTTCATTAGCAATTAATAAAGCTATACATGC

FIG. 2. CDNA and predicted amino acid sequences. The cDNA clone was isolated by screening a pACT cDNA library (Clontech Laboratories) with pGBT9/RAD51 according to the manufacturer's instructions and previously described procedures (see Materials and Methods). $\mathrm{His}^{-}$-selected positive clones were LacZ assayed in HF 7c cells using a different promoter. Yeast clone plasmids were isolated and electroporated into HB101 cells. Growth in M9 (Leu ${ }^{-}$) minimal media resulted in selection of bacteria containing only the PACT vector. Purified $\mathrm{pACT}$ plasmids were sequenced with an $\mathrm{ABI}$ 373A automatic DNA sequencer ( $A B \mathrm{BI}$ Biosystems) by using a primer-walking strategy. Bidirectional sequencing and at least two independent sequencing reactions were performed to obtain the cDNA sequence. A potential poly $(A)$ addition signal in the CDNA is underlined. The sequence has been deposited with GenBank under Accession No. U 38784
UBL1 I MSD . . . QEAKPSTEDLGDKKEGEYIKLKVIGODSSETHFKVKMTTHLKK 46

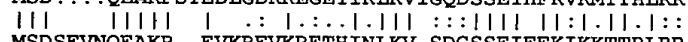
SCSMT3 1 MSDSEVNQEAKP. EVKPEVKPETHINLKV.SDGSSEIFFKIKKTTPLRR 47

UBL1 47 LKESYCQRQGVPMNSLRFLFEGQRIADNHTPKELGMEEEDVIEVYQEQTG 96

SCSMT 48 LMEAFAKRQGKEMDSLRFLYDGIRIQADQTPEDIDMEDNDIIEAHREQIG 97

UBL1 97 GHSTV 101

SCSMT3 98 GATY 101

UBL1 22 IKLKVIGQDSSEIHFKVKMTTHLKKLKESYCQRQGVPMNSLRFLFEGQRI 71 Ub. $\quad 1$ MQIFVKTLTGKTITLEVEPSDTIENVKAKIQDKEGIPPDQQRLIFAGKQL 50

UBLI 72 ADNHTPKELGMEEEDVIEVXQEQTGGHSTV 101

ub. $\quad 51$ EDGRTLSDYNIQKESTLHLVLRIRGG 7

UBL1 19 GEYIKLKVIGQDSSEIHFKVKMTTHLKKLK. ESYCQRQGVPMNSLRFIFE 67

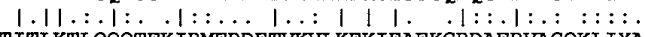

HHR23A 2 AVTITLKTLQQQTFKIRMEPDETVKVLKEKIEAEKGRDAFPVAGQKLIYA 51

UBL1 68 GQRIADNHTPKELGMEEEDVIEVYQEQT.GGHST 100

HHR23A 52 GKILSDDVPIRDYRIDEKNFVVVMVTKTKAGQGT 8

UBL1 22 IKLKVIGQDSSEIHFKVKMTTH. LKKLKESYCQRQGVPMNSLRFLFEGQR 70 HHR23B 3 VTLKTLQQ UBL1 71 IADNHTPKELGMEEEDVIEVYQEQTGGHSTV 101

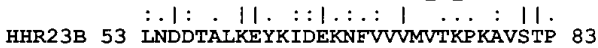

UBL1 2 SDQEAKPSTEDLGDKKEGEYIKLKVIGQDSSEIHFKVKMTTHLKKLKESY 51

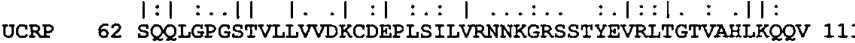

UBL1 52 CQRQGVPMNLRFIFEGQRIADNHTPKELGMEEEDVIEVYQEQTG 96

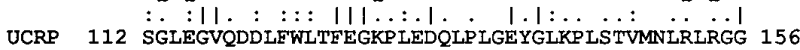

FIG.3. Alignment of the UBL 1 amino acid sequence with those of the yeast SMT3 protein (GenBank Accession No. U33057), ubiquitin, human RAD23A (HHR23A), human RAD23B (HHR23B), and a ubiquitin cross reacting protein (UCRP). The alignment was performed with the BESTFIT program in the GCG sequence analysis software package (University of Wisconsin, Madison).

CDNA, human RAD51 cDNA, and human $\beta$-actin CDNA (provided with the blot), with stripping between each hybridization according to the protocol provided with the membrane. Hybridization probes were labeled with a random labeling kit (Amersham Corp., Arlington Heights, IL).

Other molecular methods. Primers were synthesized with an Applied Biosystems Model 394 synthesizer. pGAD424/UBL 1 was constructed by fusing bases $67-375$ (Fig. 2) to the Gal4 DNA activation domain in vector pGAD424, and pGBT424/hRAD12 was constructed by fusing bases $67-375$ (Fig. 2) to the Gal4 DNA binding domain in pGBT9 vector by PCR using BamHI- and Sall-tagged primers. Detailed procedures and construction of other two-hybrid vectors have been described previously (Shen et al., 1996a).

\section{TABLE 1}

\section{Homology between UBL1 and SMT3, Ubiquitin, and Other Ubiquitin-like Proteins}

UBL1 SMT3 Ubiquitin HHR23A HHR23B UCRP

UBL $1 \quad 100 \%$

SMT3 $\quad 72 \% \quad 100 \%$

Ubiquitin $\quad 45 \% \quad 43 \%$

HHR23A $\quad 52 \% \quad 38 \%$

HHR23B $48 \% \quad 44 \%$

UCRP

$43 \% \quad 43 \%$

$67 \%$
$70 \%$
$60 \%$

$100 \%$

$70 \% \quad 82 \%$

$41 \% \quad 100 \%$

Note The BESTFIT program in the GCG package was used for sequence analysis. Only the $\mathrm{N}$-terminal 85 amino acids were compared for HHR23A and HHR23B. 
A

\section{Gal4 DNA Binding Domain Fusion Prot eins}

Gal4 DNA Activation Domain Fusion Proteins

Gal4-DB DIV

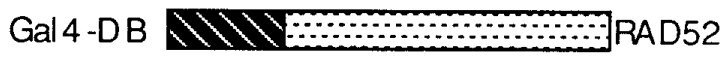

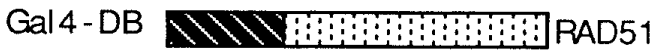

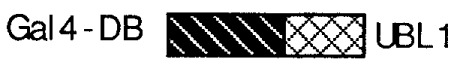

Gal4-DB MIMIMIMp53, a.a. 72-393

B

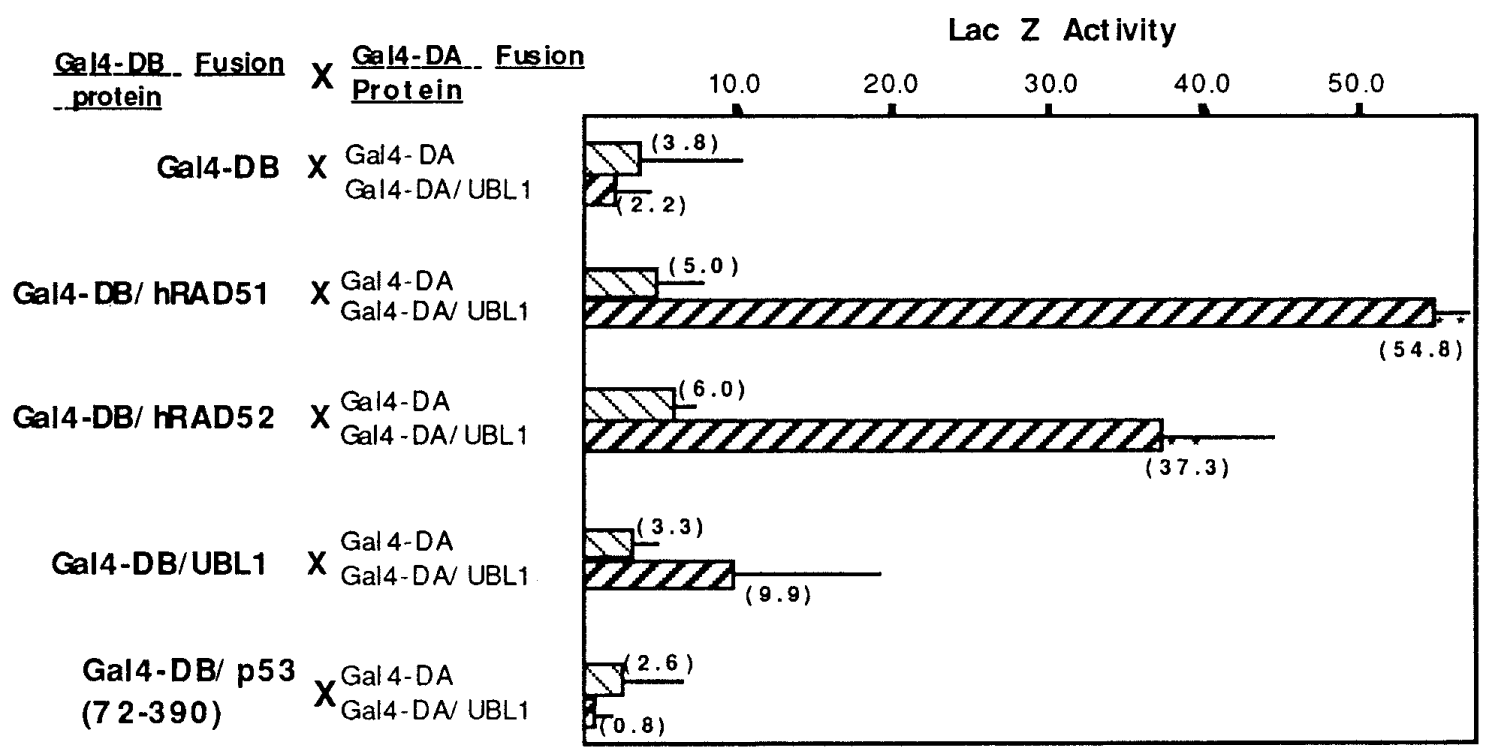

FIG. 4. Interaction of UBL1 with RAD51 and RAD52 in a yeast two-hybrid system. (A) Interaction of UBL 1 with other proteins by LacZ filter assay. (B) Quantitative LacZ assay for UBL 1's interaction with other proteins. The numbers in parentheses are the average LacZ activity of at least three independent colonies. Error bars indicate the standard errors. Experimental procedures for two-hybrid liquid assay and LacZ unit definition can be found under Materials and Methods. ** LacZ activity is statistically higher than that in the controls as tested by Student's t test $\left(P_{1}<0.001\right)$.

\section{RESULTS}

cDNA Cloning and Sequence Analysis

UBL 1 was identified from a pACT vector-based library through its interaction with the human RAD51 (hRAD51) protein in a two-hybrid system utilizing $\mathrm{His}$ and LaCZ as selection genes in the HF 7c yeast strain (Clontech Laboratories). Subsequently, a 1017-bp CDNA was isolated from $0.3 \times 10^{6}$ independent clones (Fig. 2). The cDNA contains an open reading frame starting at base 67 and ending at base 369 (Fig. 2). Because of the characteristic base $A$ at position 64 (Kozak, 1984), bases 67-69 were assigned as the translation start codon. This open reading frame codes for a protein of 101 amino acids with a molecular mass of $12 \mathrm{kDa}$.
Comparison of the amino acid sequence with nonredundant protein databases (including GenBank, SwissPort, PIR, etc.) showed no direct match. However, a yeast protein, SMT3 (GenBank Accession No. U33057), has $72 \%$ similarity and $52 \%$ identity with UBL 1 (Fig. 3). Also, many proteins in the ubiquitin family showed moderate homology (40-55\% similarity, 20\% identity) to UBL1. Figure 3 shows the alignment of the UBL 1 protein sequence to human ubiquitin (Callis et al., 1989) and several ubiquitin-likeproteins, including the $\mathrm{N}$-terminal 85 amino acids of the human RAD23 proteins (Masutani et al., 1994; van der Spek et al., 1994) and an interferon-inducible protein (UCRP) (Loeb and Haas, 1992, 1994). Table 1 summarizes the homology between the above-mentioned ubiquitin-like proteins. 
A
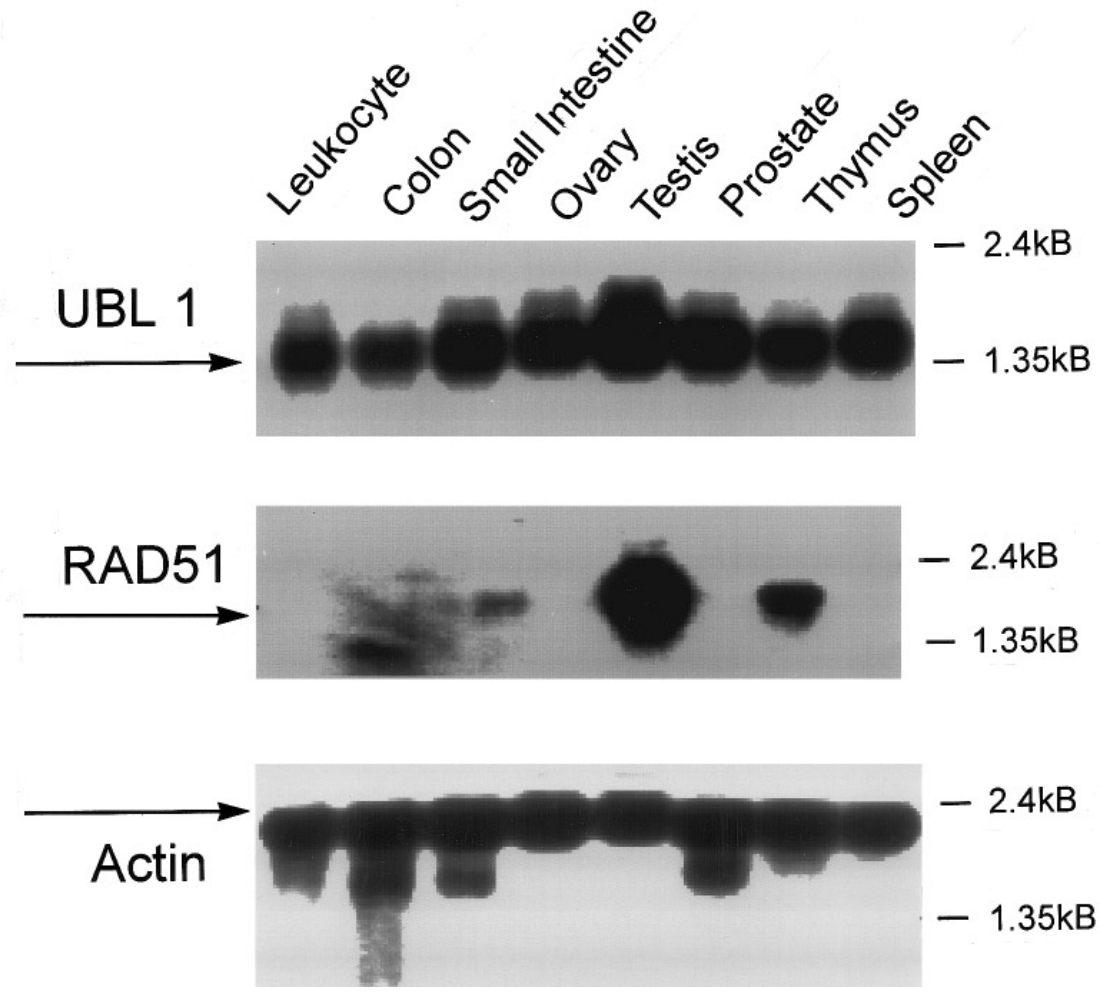

B

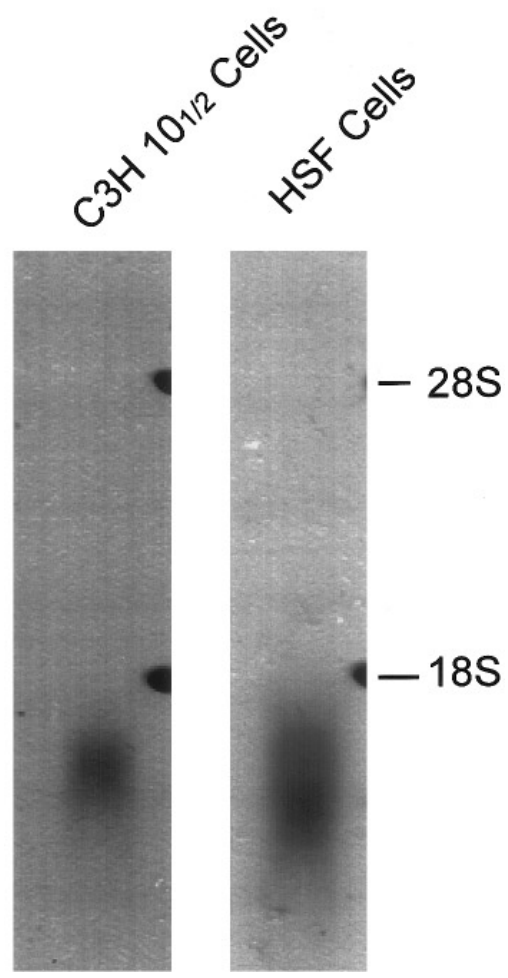

FIG.5. mRNA analysis of UBL1. (A) Multipletissue mRNA blot (Clontech Laboratories) with $2 \mu$ g of mRNA on each lane was sequentially hybridized with UBL1 CDNA probe, human RAD51 CDNA probe, and $\beta$-actin probe according to the manufacturer's protocol, with stripping between each hybridization. (B) Northern analysis of UBL1 in human skin fibroblast (HSF) and C3H mouse $10_{\frac{1}{2}}^{\frac{1}{2}}$ embryo fibroblast (C3H $10 \frac{1}{2}$ cells). The procedure is as described previously (Shen et al., 1995).

\section{UBL 1 I nteracts with Human RAD52 as well as with RAD51}

To confirm its interaction with hRAD51, only the coding region of UBL 1 was fused to the Gal 4 DNA activation domain in vector pGAD424, which contains a weaker promoter than the PACT vector (Clontech Laboratories). This fusion also eliminated the noncoding region at the $5^{\prime}$-end of UBL 1 CDNA. UBL 1's interaction with hRAD51 was further tested in another yeast strain, SFY 526 (Clontech Laboratories), using LaCZ as the reporter gene. As shown in Fig. 4, neither the vector alone nor UBL 1 itself activated the expression of LacZ. Cotransfection of pVD3 (amino acids 72-390 of p53 fused to the Gal4 DNA binding domain in the pGBT9 vector) or $\mathrm{pGBT} 9 / \mathrm{UBL} 1$ with pGAD424/UBL 1 did not activate the $L a c Z$ gene, indicating no association of UBL1 with the truncated p53 nor UBL1 itself. However, when pGBT9/RAD51 or pGBT9/hRAD52 was cotransfected with pGAD424/UBL1, the LacZ gene was activated, indicating an association of UBL1 with hRAD51 as well as hRAD52.

\section{Expression of UBL1 and Human RAD51 mRNA in Testis}

Since it has been shown that the human RAD51 mRNA is highly expressed in testis where meiosis and mitosis are active (Shinohara et al., 1993), we further examined the UBL1 mRNA level in several tissues, including testis, by Northern blot (Fig. 5A). It is evident that, although UBL1 mRNA is expressed in all the tissues tested, testis exhibits the highest level of mRNA, which is consistent with human RAD51.

Northern hybridization to human and mouse total RNA showed a single mRNA species of $1.3-1.4 \mathrm{~kb}$ (Fig. $5 B$ ), indicating that transcripts of this gene exist in human and mouse cells. Since the average poly(A) tail in an mRNA is about 250 bases (Birnstiel et al., 1985) and a putative poly(A) addition site (AATAAA) is identified in the 1017-bp cDNA clone (Fig. 2), this CDNA clone (Fig. 2) is at least close to full length.

\section{Chromosome Localization of UBL 1}

The chromosome localization of UBL1 was determined by FISH analysis using the full-length CDNA as a probe (Heng et al., 1992; Heng and Tsui, 1993, 1994). Among 100 cells examined, 50 showed paired chromatid signals from chromosome $2 q$ only (Figs. $6 A$ and $6 B$ ), 7 showed paired chromatid signals from chromosome 1q only, 32 showed signals from both chromosomes 1q and $2 q$ (Figs. 6C and 6D), and 4 showed paired chromatid signals from chromosome 5 (data not shown). Therefore, $82 \%$ of the cells showed signals from chromosome $2 q$, and $39 \%$ of the cells showed signals from chromosome 1q. To define the regional localization further, 10 

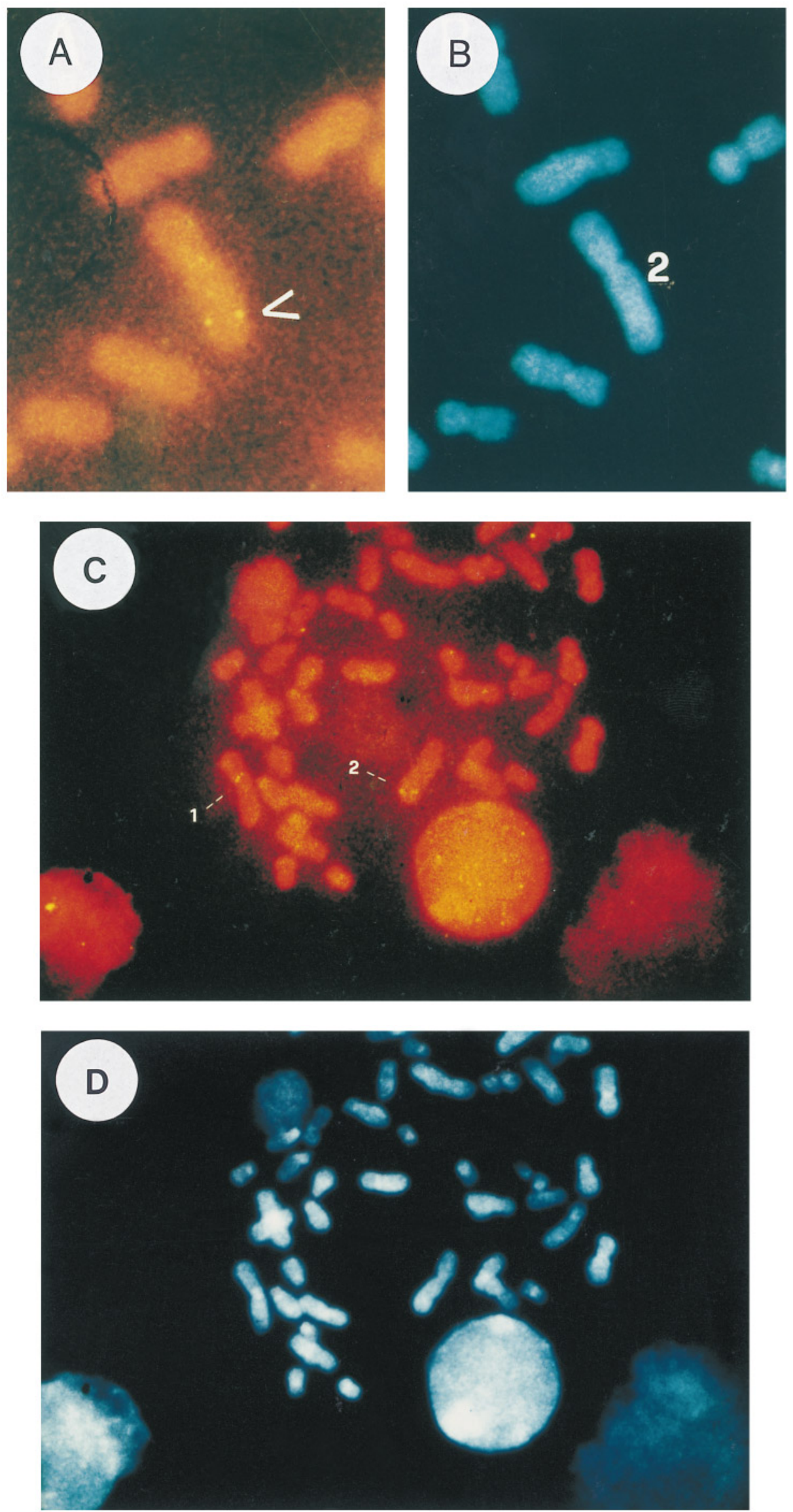

FIG. 6. Chromosome localization of the UBL1 gene. (A and B) CDNA FISH (A) and DAPI banding (B) analysis of UBL1 showing the localization on chromosome 2q. (C and D) Signals can be seen from both chromosome 1q and chromosome 2q. See Materials and Methods for technical details. 


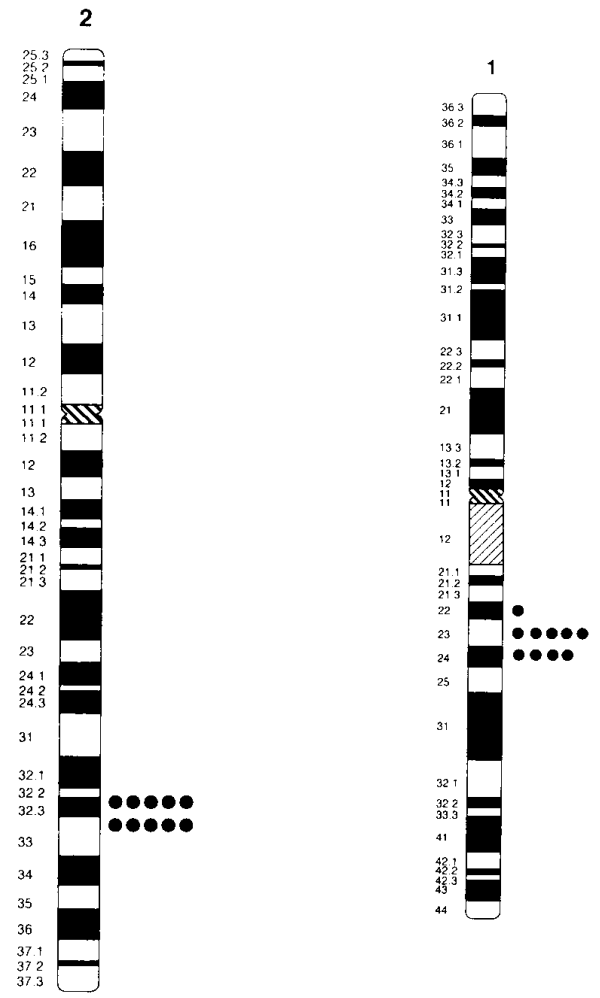

FIG. 7. Detailed analysis of 10 individual cells showing the signal localization at 2q32.3- q33 and 1q23- q24 (drawing not to scale).

individual cells were analyzed by comparing the locations of FISH signals with chromosome banding (Fig. 7). Based on these data, we concluded that UBL1 is located on 2q32.3-q33 and that a closely related sequence is located on 1q23-q24.

To confirm the chromosome localization, DNAs from a panel of rodent hybrids, each containing only a single human chromosome, were used for PCR analysis as described previously (Shen et al., 1995). Figure 8A shows that a signal identical to total human DNA was amplified from human chromosomes 1, 2, and 5 and a weaker signal from chromosome 13 , indicating the presence of sequences closely related to UBL 1 on these chromosomes.

We have also searched GenBank for homologous DNA sequences and found that several expressed sequence tags (ESTs) in GenBank have significant nucleic acid identity with UBL1 CDNA. Two of them (Accession Nos. R17443 and T16960) have 99\% identity with UBL 1 in a region of $\sim 400 \mathrm{bp}$, presumably because they are ESTs from UBL 1 directly. One (GenBank ACcession No. T08096) has $62 \%$ identity with UBL 1 cDNA in a region of $234 \mathrm{bp}$. Another (GenBank Accession No. T08856) has $57 \%$ identity in a region of $184 \mathrm{bp}$. The last two entries have $81 \%$ of the nucleic acids identical in a region of $212 \mathrm{bp}$. Therefore, a family of UBL 1 homologous genes may exist in the mammalian genome. This may explain why signals from other chromosomes are detectable.

Toconfirm the regional localization on chromosome 2 further, a panel of human radiation hybrids containing partial human chromosome 2 (Chen et al., 1994) were used for regional mapping by PCR analysis (Fig. 8B). As shown in Fig. 8B, while DNA from cell lines containing the region 2q32.3-q33 (cell lines 6CS-5, XHB78, 6x(neo2)-18, and XRV15b(neo2)-11) showed a positive PCR result, cell lines not containing this region (cell lines 6CS-7 and XHB-104) showed negative PCR results. These data confirmed the localization to 2q32.3-q33.

\section{DISCUSSION}

Similar to ubiquitin, ubiquitin-like proteins seem to be involved in many cellular processes. For example, a UCRP has been shown to be conjugated to many cellular proteins that are distributed in a cytoskeleton pattern. The $\mathrm{N}$-terminal amino acids homologous to ubiquitin in RAD23 proteins arealso essential for RAD23's DNA repair function (Pejovic, 1995).

The location of UBL 1 to $2 q 32.3-q 33$ and a related gene on 1q23-q24 is worthy of discussion. The $2 q 33$ region has been identified as an aphidicolin-inducible fragile site (Tedeschi et al., 1992), and several cancer cells, such as human small-cell lung carcinoma (Kohno et al., 1994) and ependymomas (Rogatto et al., 1993), have chromosome changes within the region $2 q 32$ q33. A potential tumor suppressor gene has also been mapped to 1q23-q24 (Horikawa et al., 1995). Genetic changes on 1q23- q25 have been observed in ovarian cancers and in Burkitt lymphoma-derived cell lines (Polito et al., 1995).

RAD51 shares a moderate sequence homology and some functional similarity (such as DNA binding and filament formation along DNA strands) with the bacterial recombination protein RecA (Benson et al., 1994; Ogawa et al., 1993; Shinohara et al., 1992; 1993). The human RAD52 protein shares significant homology with the yeast RAD52 protein only at the $\mathrm{N}$-terminus (Muris et al., 1994; Shen et al., 1995). Two independent functional domains involved in self-interaction and interaction with RAD51 have been identified (Shen et al., 1996a,b). In addition, expression of human RAD52 in monkey cells enhances radiation resistance (Park, 1995). UBL 1's yeast homolog, SMT3, is a suppressor of the yeast gene MIF 2 mutation (see GenBank Accession No. U33057). MIF2 protein is a yeast centromere protein with homology to the mammalian centromere protein CENP-C (Brown, 1995; Meluh and Koshland, 1995). MIF2 is also involved in yeast chromosome segregation (Brown et al., 1993). These results may therefore suggest that UBL 1 is also involved in mitosis. Coincidentally, human RAD51 is highly expressed during the S/G2/M phase of the cell cycle in mammalian cells, and human RAD52 in the G2/M phase (unpublished data). We have cloned a human homolog of yeast ubiquitin-conjugation enzyme UBC9, which is involved in S- and M-phase cyclin degradation (Seufert et al., 1995) and mitosis control (Al-Khodairy et al., 1995). This hUBC9-like protein also interacts with UBL1, hRAD52, hRAD51, and p53 proteins (Shen et al., 

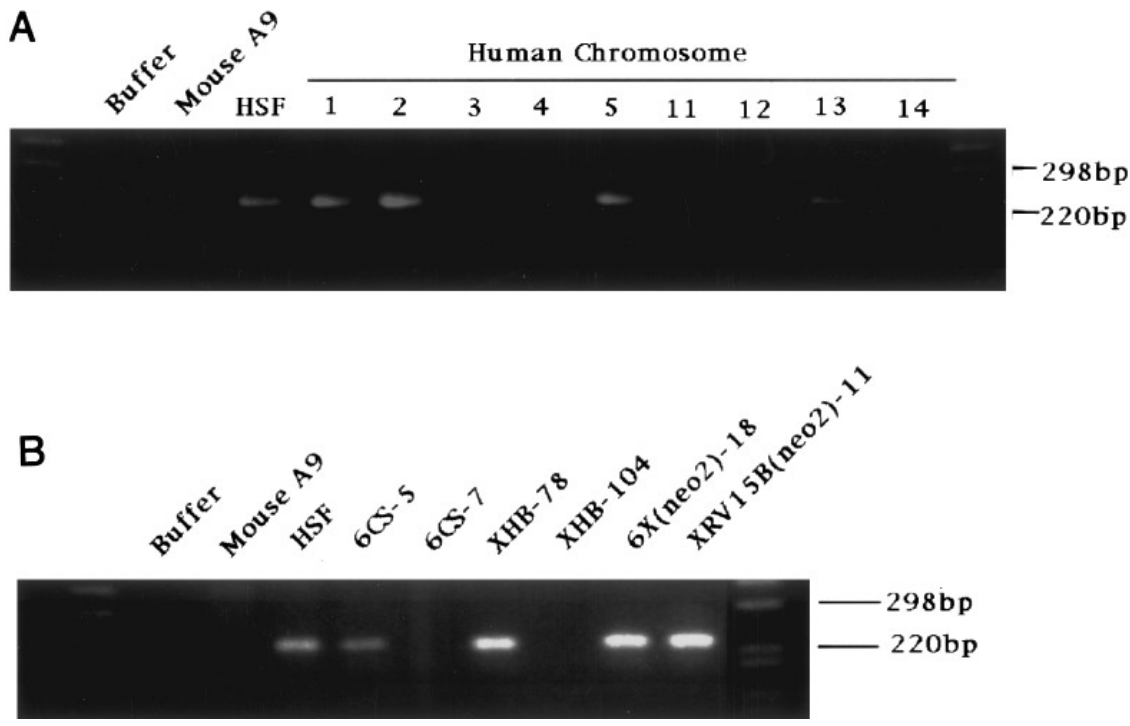

FIG. 8. PCR analysis of human chromosome hybrids in mouse cells as described before. (A) PCR from chromosomes $1,2,3,4,5,11$, 12,13 , and 14 are shown. "Buffer" denotes negative control using buffer al one as the PCR template, "mouse A9" indicates DNA from mouse A9 cells from which the hybrid panel was constructed, and "HSF" denotes total DNA from human skin fibroblast. Other lanes are molecular size markers. PCR results from other human chromosomes are negative and not shown. The primers used are 5'GGTGATCAAGCCTCAGTC (positions 552-569 in Fig. 2) and 5'CCACAGTTCAGTTCTCTG (positions 791-774 in Fig. 2). (B) A few X-ray hybrids, containing partial human chromosome 2, were further analyzed by PCR. Labels at the top denote the cell lines used; other labels are the same as in A. While DNA from cell lines containing the region 2q32.3- q33 (cell lines 6CS-5, XHB-78, 6x(neo2)-18, and XRV15b(neo2)-11) showed a positive PCR result, cell lines not containing this region (cell lines 6CS-7 and XHB-104) showed negative PCR results. For detailed information about these cell lines, please refer to Chen et al. (1994).

1996c). Therefore, we believe the association of UBL1 with RAD51/RAD52 to be functionally relevant. The association of UBL1 and hRAD51/hRAD52 also suggests that DNA repair/recombination pathways and cell cycle/mitosis control pathways may interface with each other.

\section{ACKNO WLEDGMENTS}

This research was supported by the U.S. Department of Energy and NIH Grant CA50519 to D.J .C. and by a Director's postdoctoral fellowship from Los Alamos National Laboratory to Z.S. We thank Drs. Morton E. Bradbury, Scott Peterson, and Robert Cary for hel pful discussions and critical reading of the manuscript.

\section{REFERENCES}

Adzuma, K., Ogawa, T., and Ogawa, H. (1984). Primary structure of the RAD52 gene in Saccharomyces cerevisiae Mol. Cell. Biol. 4: 2735- 2744.

Alani, E., Subbiah, S., and Kleckner, N. (1989). The yeast RAD50 geneencodes a predicted 153-kD protein containing a purine nucleotide-binding domain and two large heptad-repeat regions. Genetics 122: 47- 57.

Al-Khodairy, F., Enoch, T., Hagan, I. M., and Carr, A. M. (1995). The Schizosaccharomyces pombe hus5 gene encodes a ubiquitin conjugating enzyme required for normal mitosis. J . Cell Sci. 108: 475-486.

Basile, G., Aker, M., and Mortimer, R. K. (1992). Nucleotide sequence and transcriptional regulation of the yeast recombinational repair gene RAD51. Mol. Cell. Biol. 12: 3235- 3246.

Benson, F. E., Stasiak, A., and West, S. C. (1994). Purification and characterization of the human Rad51 protein, an analogue of $E$. coli RecA. EMBO J. 13: 5764-5771.

Birnstiel, M. L., Busslinger, M., and Strub, K. (1985). Transcription termination and 3' processing: The end is in site. Cell 41: 349359.

Brown, M. T. (1995). Sequence similarities between the yeast chromosome segregation protein Mif2 and the mammalian centromere protein CENP-C. Gene 160: 111- 116.

Brown, M. T., Goetsch, L., and Hartwell, L. H. (1993). MIF2 is re quired for mitotic spindle integrity during anaphase spindle elongation in Saccharomyces cerevisiae J . Cell Biol. 123: 387-403.

Callis, J ., Pollmann, L., Shanklin, J ., Wettern, M., and Vierstra, R. (1989). Sequence of a cDNA from Chlamydomonas reinhardii encoding a ubiquitin 52 amino acid extension protein. Nucleic Acids Res. 17: 8377.

Chen, D. J ., Marrone, B. L., Nguyen, T., Stackhouse, M., Zhao, Y., and Siciliano, M. J . (1994). Regional assignment of a human DNA repair gene (XRCC5) to 2q35 by X-ray hybrid mapping. Genomics 21: $423-427$.

Cole, G. M., Schild, D., and Mortimer, R. K. (1989). Two DNA repair and recombination genes in Saccharomyces cerevisiae, RAD52 and RAD54, are induced during meiosis. Mol. Cell. Biol. 9: 3101- 3104.

Emery, H. S., Schild, D., Kellogg, D. E., and Mortimer, R. K. (1991). Sequence of RAD54, a Saccharomyces cerevisiae gene involved in recombination and repair. Gene 104: 103-106.

Firmenich, A. A., Elias-Arnanz, M., and Berg, P. (1995). A novel allele of Saccharomyces cerevisiaeRFA1 that is deficient in recombination and repair and suppressible by RAD52. Mol. Cell. Biol. 15: $1620-1631$.

Friedberg, E., Siede, W., and Cooper, A. (1991). Cellular response to DNA damage in yeast. In "The Molecular and Cellular Biology of the Yeast Saccharomyces" (J . Broach, J . R. Pringle, and E. J ones, Eds.), pp. 147-192, Cold Spring Harbor Laboratory Press, Cold Spring Harbor, NY.

Haaf, T., Golub, E. I., Reddy, G., Radding, C. M., and Ward, D. C. (1995). Nuclear foci of mammalian Rad51 recombination protein in somatic cells after DNA damage and its localization in synaptonemal complexes. Proc. Natl. Acad. Sci. USA 92: 2298- 2302. 
bination of psoralen damaged plasmid DNA in Saccharomyces cere visiae Mol. Gen. Genet. 236: 8-16.

Hays, S. L., Firmenich, A. A., and Berg, P. (1995). Complex formation in yeast double-strand break repair: Participation of Rad51, Rad52, Rad55, and Rad57 proteins. Proc. Natl. Acad. Sci. USA 92 6925-6929.

Heng, H. H., Squire, J ., and Tsui, L. C. (1992). High-resolution mapping of mammalian genes by in situ hybridization to free chromatin. Proc. Natl. Acad. Sci. USA 89: 9509-9513.

Heng, H. H., and Tsui, L. C. (1994). FISH detection on DAPI-banded chromosomes. Methods Mol. Biol. 33: 35-49.

Heng, H. H., and Tsui, L. C. (1993). Modes of DAPI banding and simultaneous in situ hybridization. Chromosoma 102: 325- 332.

Horikawa, I., Yamada, H., Kugoh, H., Yuasa, Y., Suzuki, M., and Oshimura, M. (1995). Subchromosomal mapping of a putative transformation suppressor gene on human chromosome 1. J pn. J . Cancer Res. 86: 444- 450.

Kans, J . A., and Mortimer, R. K. (1991). Nucleotide sequence of the RAD57 gene of Saccharomyces cerevisiae. Gene 105: 139- 140.

Kohno, T., Morishita, K., Takano, H., Shapiro, D. N., and Yokota, J . (1994). Homozygous del etion at chromosome 2q33 in human smallcell lung carcinoma identified by arbitrarily primed PCR genomic fingerprinting. Oncogene 9: 103-108.

Kozak, M. (1984). Compilation and analysis of sequences upstream from the translational start site in eukaryotic mRNAs. Nucleic Acids Res. 12: 857-872.

Loeb, K. R., and Haas, A. L. (1994). Conjugates of ubiquitin crossreactive protein distribute in a cytoskeletal pattern. Mol. Cell. Biol. 14: 8408-8419.

Loeb, K. R., and Haas, A. L. (1992). The interferon-inducible 15kDa ubiquitin homolog conjugates to intracellular proteins. J . Biol . Chem. 267: 7806-7813.

Lovett, S. T. (1994). Sequence of the RAD55 gene of Saccharomyces cerevisiae: Similarity of RAD55 to prokaryotic RecA and other RecA-like proteins. Gene 142: 103- 106.

Masutani, C., Sugasawa, K., Yanagisawa, J ., Sonoyama, T., Ui, M., Enomoto, T., Takio, K., Tanaka, K., van der Spek, P. J ., Bootsma, D., et al. (1994). Purification and cloning of a nucleotide excision repair complex involving thexeroderma pigmentosum group $\mathrm{C}$ protein and a human homologue of yeast RAD23. EMBO J . 13: 18311843.

Meluh, P., and Koshland, D. (1995). Evidence that the MIF2 gene of Saccharomyces cerevisiae encodes a centromere protein with homology to the mammalian centromere protein CENP-C. Mol. Biol. Cell 6: 793-807.

Miller, J . (1972). "Experiments in Molecular Genetics," Cold Spring Harbor Laboratory Press, Cold Spring Harbor, NY.

Muris, D. F., Bezzubova, O., Buerstedde, J . M., Vreeken, K., Balajee, A. S., Osgood, C. J ., Troelstra, C., Hoeijmakers, J . H., Ostermann, K., Schmidt, H., et al. (1994). Cloning of human and mouse genes homologous to RAD52, a yeast gene involved in DNA repair and recombination. Mutat. Res. 315: 295- 305.

Ogawa, T., Yu, X., Shinohara, A., and Egelman, E. H. (1993). Similarity of the yeast RAD51 filament to the bacterial RecA filament. Science 259: 1896- 1899.

Park, M. S. (1995). Expression of human RAD52 confers resistance to ionizing radiation in mammalian cells. J . Biol. Chem. 270: 1546715470.

Pejovic, T. (1995). Genetic changes in ovarian cancer. Ann. Med. 27: 73- 78.
Polito, P., Cilia, A. M., Gloghini, A., Cozzi, M., Perin, T., De Paoli, P., Gaidano, G., and Carbone, A. (1995). High frequency of EBV association with non-random abnormalities of the chromosome re gion 1q21-25 in AIDS-related Burkitt's Iymphoma-derived cell lines. Int. J . Cancer 61: 370-374.

Rogatto, S. R., Casartelli, C., Rainho, C. A., and Barbieri-Neto, J . (1993). Chromosomes in the genesis and progression of ependymomas. Cancer Genet. Cytogenet. 69: 146- 152.

Saffran, W. A., Cantor, C. R., Smith, E. D., and Magdi, M. (1992). Psoralen damage-induced plasmid recombination in Saccharomyces cerevisiae: Dependence on RAD1 and RAD52. Mutat. Res. 274: 1-9.

Sanchez, Y., Desany, B. A., J ones, W. J ., Liu, Q., Wang, B., and Elledge, S. J . (1996). Regulation of RAD53 by the ATM-like kinases MECl and TEL 1 in yeast cell cycle checkpoint pathways [see comments]. Science 271: 357-360.

Schild, D., Konforti, B., Perez, C., Gish, W., and Mortimer, R. (1983). I solation and characterization of of yeast DNA repair genes: Cloning of the RAD52 gene. Curr. Genet. 7: 85-92.

Seufert, W., Futcher, B., and J entsch, S. (1995). Role of a ubiquitinconjugating enzyme in degradation of S- and M-phase cyclins. Nature 373: 78- 81.

Shen, Z., Denison, K., Lobb, R., Gatewood, J . M., and Chen, D. J . (1995). The human and mouse homologs of the yeast RAD52 gene: cDNA cloning, sequence analysis, assignment to human chromosome 12p12.2- p13, and mRNA expression in mouse tissues. Genomics 25: 199-206.

Shen, Z., Cloud, G., Chen, D., and Park, M. (1996a). Specific interaction between human RAD51 and RAD52 proteins. J . Biol. Chem. 271: 148- 152.

Shen, Z., Peterson, S., Comeaux, J ., Zastraw, D., Moyzis, R., Bradbury, E., and Chen, D. (1996b). Self-association of human RAD52 protein. Mutat. Res. DNA Repair, in press.

Shen, Z., Pardington-Purtymum, P. E., Comeaux, J. C., Moyzis, R. K., and Chen, D.J . (1996c). Associations of UBE2I with RAD52, UBL1, p53, and RAD51 proteins in a yeast two hybrid system. Submitted for publication.

Shinohara, A., Ogawa, H., Matsuda, Y., Ushio, N., Ikeo, K., and Ogawa, T. (1993). Cloning of human, mouse and fission yeast recombination genes homologous to RAD51 and recA Nature Genet. 4: 239- 243. [Published erratum appears in Nature Genet. 1993, 5(3): 312.]

Shinohara, A., Ogawa, H., and Ogawa, T. (1992). Rad51 protein involved in repair and recombination in S. cerevisiae is a RecA-like protein. Cell 69: 457-470. [Published erratum appears in Cell, 1992, 71(1): following 180.]

Smith, J ., and Rothstein, R. (1995). A mutation in the gene encoding the Saccharomyces cerevisiae single-stranded DNA-binding protein Rfal stimulates a RAD52-independent pathway for directrepeat recombination. Mol. Cell. Biol. 15: 1632-1641.

Tedeschi, B., Vernole, P., Sanna, M. L., and Nicoletti, B. (1992). Population cytogenetics of aphidicolin-induced fragile sites. Hum. Genet. 89: 543-547.

van der Spek, P. J., Smit, E. M., Beverloo, H. B., Sugasawa, K., Masutani, C., Hanaoka, F., Hoeijmakers, J. H., and Hagemeijer, A. (1994). Chromosomal localization of three repair genes: The xeroderma pigmentosum group $\mathrm{C}$ gene and two human homologs of yeast RAD23. Genomics 23: 651-658.

Zheng, P., Fay, D. S., Burton, J ., Xiao, H., Pinkham, J . L., and Stern, D. F . (1993). SPK 1 is an essential S-phase-specific gene of Saccharomyces cerevisiaethat encodes a nuclear serine/threonine/tyrosine kinase. Mol. Cell. Biol. 13: 5829-5842. 